\title{
English Teachers' Perspectives on Using Music in English Language Teaching in Thai Secondary Schools
}

\author{
Xiaowei Xi \\ Language Institute, Thammasat University, Bangkok, Thailand
}

\begin{abstract}
The present study aimed to 1) investigate English teachers' perspectives on using music in English teaching in Thai secondary schools; and 2) explore the problems teachers met while using music to teach English in Thai secondary schools. Participants in the present study were 55 English teachers from different secondary schools in central Bangkok, Thailand. The instrument for the current study was a questionnaire which included 24 Likert-scale items about teachers' perspectives involving the attitudes, beliefs, intentions and problems of using music in English teaching, and one open-ended question asking about the problems teachers met while using music in their English teaching. Results from the quantitative data of the current study revealed the significantly positive attitudes and beliefs of the English teachers in Thai secondary schools on using music in English teaching, however, the results of open-ended question mismatched with the teachers' attitudes and beliefs, which indicated that teachers actually did not use music in their English teaching frequently. The reasons and recommendations for future research have been discussed.
\end{abstract}

Index Terms—music in English teaching, teachers' perspectives, English language teaching

\section{INTRODUCTION}

In recent years, more and more scientific research studies have sprung up, showing the evolutionary evidence that music and language share a lot of commons such as music is being regarded as the universal language of human beings (Mora, Fuentes \& Wermke, 2011), since both of music and language have the communicative characteristic as the conveying methods of human and they can stimulate the human emotions (Dobrian, 1992); and both language and music have their own fixed rules of sequences; that is, rules for language to make a sentence and for music to make a melody (Patel, 2003); also both of them are culture-related (Murphey, 1992b).

Music is beneficial to language learning in several aspects. First of all, music could increase the learner's phonological awareness (Hallam, 2010). Taking Posedel's (2012) experiment as an example, they explored the Englishspeaking students who were studying Spanish as the second language to check the correlation between their music training and L2 pitch perception ability, the results suggested that musical training could enhance the ability of pitch perception. For another example, the experiment was conducted by Bidelman, Hutka and Moreno (2013) to examine the basic auditory as well as complex music perception among the nonmusical-trained individuals and musicians of Cantonese-speaking and English-speaking, then the results showed the bidirectional influences between music and language, which meant some languages learning could enhance the music perception and music training also have the salient benefit for language learning.

Moreover, music could support language learning in many emotional aspects. Music is enjoyable for improving motivation, and the majority of people love music, when they listen to music, the emotions would be related to the music (Mora et al., 2011), and lyrics and instrument performances of music are all the authentic materials (Mishan, 2005), which would also encourage learner's motivation, since Nunan (2004) indicated that designing the authentic activities in teaching task and the natural language input would be one stimulating factor in language learning. Then, music can reduce the learner's anxiety in language learning.

In addition, mounting studies reported that music could help enhance the learner's long- and short-term memory. For example, Murphey (1992b) pointed out that the repetition characteristic of music could make a phenomenon named the "song-stuck-in-my-head", which found as the songs could be memorized in head for a long time. In another experiment, Medina (1993) reported that learners were able to remember more words by singing rather than speaking, in other words, the more vocabulary items students heard, the more generated retention, gradually, it made student's implicit memory expanded and vocabulary increased unconsciously (Bidelman et al., 2013). Thus, to memorize the content by singing would be easier under both hemispheres' activation.

From a practical standpoint, music is not only beneficial in language learning for learners, but also helpful in language teaching for teachers as a flexible tool to support many teaching aspects. As far as teaching listening and speaking skills, listening to a foreign-language song and singing it could be a very beneficial exercise for improving listening skill, since the lyrics were full of grammatical points and cultural information (Mora et al., 2011). Moreover, as Rixon (1986) contended that the listening difficulties stemmed from pronunciation including the rhythm pattern of 
speaking English, the sound pronouncing and the speed of sounds changing. To this point, singing music should be the highly suitable and effective exercise to get familiar with the rhythmic sense, and through music exercises students would improve their abilities to identify the pitches differentiation in a sentence and the phonological perception, in turns students could precisely discriminate the individual phonemes then imitate the sounds, the stress, the intonations to practice their speaking. Meanwhile, music also can support to teach reading and writing skills. While music exercises or activities, the writing ability of language learning could be improved (Shen, 2009). Music and language were both the organized patterns with the most authentic and natural texts as mentioned above, therefore, students had more chances to see the most native-speaking expressions from the lyrics, which were the most vital components of writing ability.

Additionally, music is useful in teaching language grammar. Since lyrics in music are the organized and aligned settings of texts and sentences, which would be a suitable material to teach language semantics. And the well-aligned lyrics would be easier for students to catch up with the beats and syllables of the sentences so that music could support students to learn the word segmentation (Gordon, Magne \& Large, 2011). Therefore, materials or activities involving music would help students get familiar with the well-aligned text settings that could elicit student's linguistic understanding and increase the rhythmic attending (Gordon et al., 2011).

Music, embracing the local cultures, can be used as culture-bonded materials and activities in language teaching. Since the characteristics that music provides both cultural and linguistic elements respecting to language learning, teaching with music would lead students to realize the native-speaker's attitudes and the customs (Mora et al., 2011). Moreover, Murphey (1992a) also indicated that songs provided an important channel to show local culture for the learners who were studying as a foreign language, and singing was one of the main ways to stimulate the foreign cultures. Therefore, students would be able to understand the cultural features and values from the lyrics of music.

Considering the outside factors in language teaching, teachers could not only focus on the methods or content but also need to take care of the contexts and student's emotions which are more subjective factors in language teaching. Thus, the effects of music were not merely on academic skills, whereas the personal feeling-expression, connection with family and the community would also be developed (Campbell, 2000). Singing or chorusing in a big group could reduce student's fear of speaking English that is the ubiquitous problem of foreign language learners, while singing individually would highly establish self-confidence as one of the factors that contribute to language learning. And Mora (2000) also emphasized that teachers used music during teaching would provide a rich environment of sound and cut out the other auditory distractions, so that students could pay most attention to the activities teacher did.

However, as everyone knows that music is enjoyable and entertaining, most teachers would instinctively choose music to be a supplemental activity or to have a break during class, which can constrain the power of music in English teaching. For a better knowledge of English teachers' perspectives on employing music in their teaching, the current study covered the aspects of their personal attitudes toward music, beliefs in using music to teach English, beliefs in music benefits for English learning, teaching intentions of using music as well as the problems they faced during employing music in English teaching. Hence, the current study sought to investigate Thai secondary schools English teachers' perspectives about using music in English teaching, so that the insight of English teachers could promote the school administrators and curriculum developers to re-conceptualize the learning and academic programs, considering to attach more importance on the musical techniques and materials in language learning. Moreover, the results of this study may raise teachers' awareness of the importance of music in English teaching.

Objectives

The purposes of the current study were to 1) investigate English teachers' perspectives on using music in English teaching in Thai secondary schools; and 2) explore the problems teachers met while using music to teach English in Thai secondary schools.

\section{METHODS}

\section{A. Participants}

The participants in the current study were 55 English teachers from Thai secondary government schools in central Bangkok, Thailand, who were purposively selected and voluntarily spent time filling in the questionnaire written in English.

\section{B. Instruments}

In the present study, the questionnaire was designed by partially adapting from the Sevik's (2011) research questionnaire about exploring Turkish EFL teachers' perspectives on using music in English teaching, which was included four parts as 1) the Turkish EFL teachers' beliefs about the pedagogical value of using songs in their teaching contexts; 2) the attitudes toward using songs in their teaching; 3) the frequency they using songs; and 4) how teachers think about the effectiveness of doing so. Thus, the questionnaire in the present study was partially adapted from the previous research with three aspects which were the teachers' attitudes, beliefs and intentions of using music in English teaching. The questionnaire consisted of four parts: Part one inquired about the personal information from the participants. Part two and three were composed of 24 statements as teachers' perspectives, asking about their beliefs, attitudes, intentions and problems of using music in English teaching. The participants needed to scale one appropriate 
option from the five-point Likert scale for each statement according to their own opinions. The last part was one openended question asking about the problems that teachers faced while using music in their English teaching.

The validity and reliability coefficient of the questionnaire were proved. The reliability of the questionnaire was checked by calculating Cronbah's alpha in SPSS, the result was 0.631 , which was acceptable in terms of the research instrument. And the validity was verified by asking three language-teaching experts from the university to fill in the Item-Objective Congruence table, then, according to the experts' comments, the questionnaire was revised the language uses of items 6 and 22 to be more suitable for the secondary English teachers; then the items 20-24 about the intentions of using music in English teaching were separated as one independent part using the frequency Likert-scale from -2 (never) to +2 (always) individually in the questionnaire; and the five-point Likert scales were changed from the previous scales 1 (strongly disagree) - 5 (strongly agree) to the current scales -2 (strongly disagree) -+2 (strongly agree).

\section{Data Analysis}

The data in the current study involved two parts, the quantitative data from items 1 to 24 and the qualitative data from the open-ended question in the questionnaire. For the quantitative part, the data were analyzed by descriptive and frequency statistics using SPSS. For the qualitative part, the data from the open-ended item 25 were analyzed by using content analysis.

\section{RESULTS}

The present study was designed to investigate the teachers' perspectives on using music in English teaching, which included the attitudes, beliefs, intentions of using music and the problems teachers faced while using music in English teaching. The results for each aspect of the teachers' perspectives were demonstrated in the six tables as follows.

As can be seen in Table 1, there were three items asking about the personal attitudes of teachers towards music. Participants responded on the five-point Likert scale from -2 (strongly disagree) to +2 (strongly agree) according to their own attitudes.

TABLE 1

Teachers’ AtTitudes TOWARds Music (N=55)

\begin{tabular}{|c|c|c|c|c|c|c|c|c|c|c|}
\hline \multirow[t]{2}{*}{ Statement } & \multicolumn{2}{|c|}{+2} & \multicolumn{2}{|c|}{+1} & \multicolumn{2}{|c|}{0} & \multicolumn{2}{|c|}{-1} & \multicolumn{2}{|c|}{-2} \\
\hline & $\mathrm{n}$ & $\%$ & $\mathrm{n}$ & $\%$ & $\mathrm{n}$ & $\%$ & $\mathrm{n}$ & $\%$ & $\mathrm{n}$ & $\%$ \\
\hline 1. I like music. & 39 & 70.9 & 15 & 27.3 & 1 & 1.8 & & & & - \\
\hline 2. I observe that most of my students like music. & 28 & 50.9 & 21 & 38.2 & 4 & 7.3 & 2 & 3.6 & & - \\
\hline 3. I agree that music is enjoyable. & 42 & 76.4 & 13 & 23.6 & . & & - & & & - \\
\hline
\end{tabular}

The analysis of items 1 indicated that almost every participating teacher likes music, and all the teachers agreed music is enjoyable as showing in item 3. In item 2, 89.1\% (including 50.9\% and 38.2\%) of the teachers observed that most of their students like music.

The teachers' beliefs were investigated separately as two aspects, which were the beliefs in using music to teach English and the beliefs in music benefits for English learning. Each statement was responded on the five-point Likert scale from -2 (strongly disagree) to +2 (strongly agree) according to the participating teachers' beliefs. Firstly, in Table 2, the beliefs in using music to teach English were explored by six statements

TABLE 2

TeAChers' Beliefs In Using Music To TEACH ENGLish $(\mathrm{N}=55)$

\begin{tabular}{|c|c|c|c|c|c|c|c|c|c|c|}
\hline \multirow[t]{2}{*}{ Statement } & \multicolumn{2}{|c|}{+2} & \multicolumn{2}{|c|}{+1} & \multicolumn{2}{|c|}{0} & \multicolumn{2}{|c|}{-1} & \multicolumn{2}{|c|}{-2} \\
\hline & $\mathrm{n}$ & $\%$ & $\mathrm{n}$ & $\%$ & $\mathrm{n}$ & $\%$ & $\mathrm{n}$ & $\%$ & $\mathrm{n}$ & $\%$ \\
\hline 5. I believe that music can be used as a flexible tool in English teaching. & 28 & 50.9 & 25 & 45.5 & 2 & 3.6 & & - & & 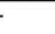 \\
\hline $\begin{array}{l}\text { 6. I believe that some appropriate English songs can be used } \\
\text { as the authentic materials for teaching. }\end{array}$ & 31 & 56.4 & 22 & 40.0 & 2 & 3.6 & & - & & - \\
\hline $\begin{array}{l}\text { 9. I believe that using music in English class can be a way to teach } \\
\text { students about culture. }\end{array}$ & 8 & 14.5 & 26 & 47.3 & 16 & 29.1 & 4 & 7.3 & 1 & 1.8 \\
\hline $\begin{array}{l}\text { 15. I believe that using music in English teaching can improve } \\
\text { students' pronunciation. }\end{array}$ & 18 & 32.7 & 23 & 41.8 & 8 & 14.5 & 4 & 7.3 & 2 & 3.6 \\
\hline $\begin{array}{l}\text { 18. I believe that using music to teach English can reduce students' anxiety } \\
\text { towards English learning. }\end{array}$ & 22 & 40.0 & 23 & 41.8 & 8 & 14.5 & 1 & 1.8 & 1 & 1.8 \\
\hline 19. I believe that using music to teach English can improve students' motivation & 28 & 50.9 & 18 & 32.7 & 7 & 12.7 & 1 & 1.8 & 1 & 1.8 \\
\hline
\end{tabular}

The analysis of items 5 and 6 indicated the majority (96.4\%) believed music could be a flexible tool in English teaching as well as believed some appropriate English songs can be used as authentic materials for teaching. Item 9 showed only $9.1 \%$ of teachers did not believe music can be a way to teach culture, and only $10.9 \%$ disagreed with using music in English teaching can improve students' pronunciation from item 15. Then, item 18 showed that $81.8 \%$ of teachers believed using music in teaching can reduce students' anxiety towards English learning, and item 19 indicated that $83.6 \%$ (including $50.9 \%$ and $32.7 \%$ ) of the teachers believed using music to teach English can improve students' motivation. 
Secondly, another aspect of teachers' beliefs was the beliefs in music benefits for English teaching, which were explored by means of four statements as shown in Table 3 below.

TABLE 3

TEACHERS’ BELIEFS IN MUSIC BENEFITS FOR ENGLISH LEARNING $(\mathrm{N}=55)$

\begin{tabular}{|c|c|c|c|c|c|c|c|c|c|}
\hline \multirow[t]{2}{*}{ Statement } & \multicolumn{2}{|c|}{+2} & \multicolumn{2}{|c|}{+1} & \multicolumn{2}{|c|}{0} & \multicolumn{2}{|c|}{-1} & -2 \\
\hline & $\mathrm{n}$ & $\%$ & $\mathrm{n}$ & $\%$ & $\mathrm{n}$ & $\%$ & $\mathrm{n}$ & $\%$ & n $\%$ \\
\hline 4. I believe that music can help students learn English. & 26 & 47.3 & 22 & 40.0 & 5 & 9.1 & 2 & 3.6 & - \\
\hline 11. I believe that music can help students remember the language content. & 16 & 29.1 & 25 & 45.5 & 13 & 23.6 & 1 & 1.8 & - \\
\hline 13. I believe that music can create a relaxing learning context for students. & 31 & 56.4 & 18 & 32.7 & 5 & 9.1 & 1 & 1.8 & - \\
\hline $\begin{array}{l}\text { 17. I believe that a large amount of repetition in music can benefit } \\
\text { students' language use. }\end{array}$ & 15 & 27.4 & 24 & 43.8 & 13 & 23.6 & 3 & 5.5 & - \\
\hline
\end{tabular}

$+2=$ strongly agree $+1=$ agree $0=$ neither agree nor disagree $-1=$ disagree $-2=$ strongly disagree

In item 4, 87.3\% (including 47.3\% and 40.0\%) believed music can help students learn English. Item 11 stated music can help students remember language content, $23.6 \%$ chose 'neither disagree nor agree', which was the same percentage of item 17 that a large amount of repetition in music can benefit students' language use, in item 17, only $5.5 \%$ of the teachers disagree. From the result of item 13, 89.1\% (including $56.4 \%$ and $32.7 \%$ ) believed that music can create a relaxing learning context for students.

As can be seen in Table 4, there were five statements in the questionnaire to investigate how often teachers used music for different intentions in their English teaching. Participants responded on the frequency Likert scale from -2 (never) to +2 (always) according to their frequency of using music in English teaching.

TABLE 4

TEACHERS’ INTENTIONS OF USING Music In ENGLISH TEACHING ( $\mathrm{N}=55)$

\begin{tabular}{|c|c|c|c|c|c|c|c|c|c|c|}
\hline \multirow[t]{2}{*}{ Statement } & \multicolumn{2}{|c|}{+2} & \multicolumn{2}{|c|}{+1} & \multicolumn{2}{|c|}{0} & \multicolumn{2}{|c|}{-1} & \multicolumn{2}{|c|}{-2} \\
\hline & n & $\%$ & $n$ & $\%$ & $\mathrm{n}$ & $\%$ & $n$ & $\%$ & $n$ & $\%$ \\
\hline 20. I use music to teach new vocabulary. & 3 & 5.5 & 12 & 21.8 & 27 & 49.1 & 4 & 7.3 & 9 & 16.4 \\
\hline 21. I use music to teach listening and speaking skills. & 4 & 7.3 & 19 & 34.5 & 16 & 29.1 & 9 & 16.4 & 7 & 12.7 \\
\hline 22. I use music to teach grammar. & 4 & 7.3 & 10 & 18.2 & 16 & 29.1 & 5 & 9.1 & 20 & 36.4 \\
\hline 23. I use music to teach reading and writing skills. & 1 & 1.8 & 11 & 20.0 & 15 & 27.3 & 10 & 18.2 & 18 & 32.7 \\
\hline 24. I use music to teach cultural features. & 3 & 5.5 & 14 & 25.5 & 18 & 32.7 & 10 & 18.2 & 10 & 18.2 \\
\hline
\end{tabular}

Results of item 20 showed that $49.1 \%$ sometimes used music to teach new vocabulary. Item 21 indicated that $41.8 \%$ (including $7.3 \%$ and $34.5 \%$ ) used music to teach listening and speaking skills as much as possible. Item 23 presented $32.7 \%$ of the teachers, as the biggest portion among the five options, never used music to teach reading and writing skills, similarly, $36.4 \%$ never used music to teach grammar in item 22 . Then, the result from item 24 indicated most of the teachers $(32.7 \%)$ sometimes used music to teach cultural features.

To investigate the problems of teachers using music in their English teaching, the questionnaire was given six statements of problems from the previous studies and one open-ended question item 25 for participants to respond to the problems they personally met while they using music in English teaching. The quantitative analysis and qualitative analysis of the results were illustrated separately in Table 5 and 6. Firstly, the quantitative analysis of six statements about teachers' problems of using music in English teaching was shown in Table 5 below.

TABLE 5

Teachers' Problems Of Using Music In ENGLish Teaching $(\mathrm{N}=55)$

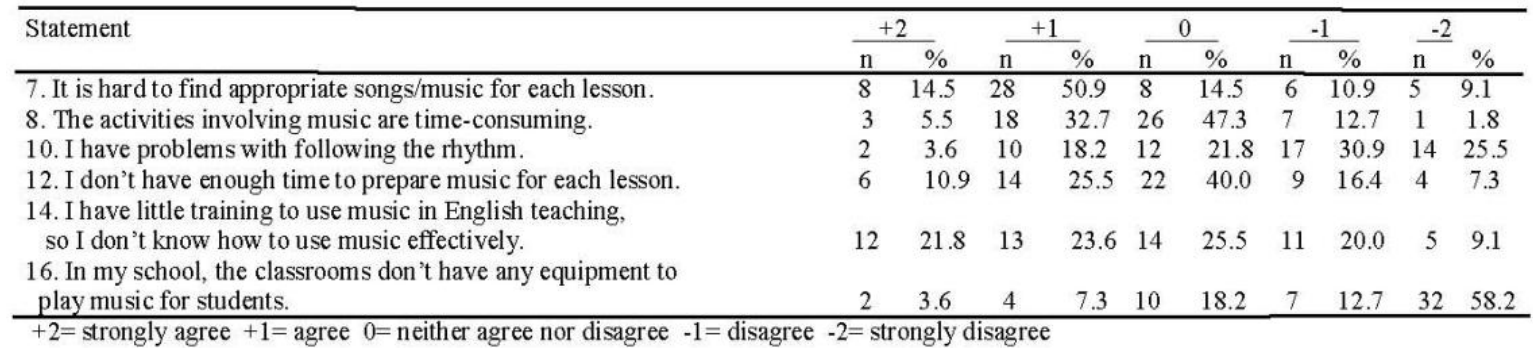

The result of item 7 indicated $65.4 \%$ (including $14.5 \%$ and $50.9 \%$ ) agreed that it is hard to find appropriate songs/music for each lesson. Then, in item $8,47.3 \%$ chose 'neither agree nor disagree' about activities involving music are time-consuming, but still many participants $(38.2 \%)$ agreed so. Item 10 revealed that the majority $(56.4 \%)$ of the participating teachers did not think they have problems with following the rhythm. The result in item 12 showed that $40 \%$ neither agreed nor disagreed about the teachers don't have enough time to prepare the music for each lesson. Most of the teachers $(45.4 \%)$ indicated that they have little training to use music in English teaching, so they don't know how to use music effectively. Then, the result from item 16 revealed that a large part of the teachers $(70.9 \%)$ disagreed with the statement that classrooms don't have any equipment to play music for students in their schools. 
Apart from the problems mentioned above, there were some other problems teachers responded in the open-ended question. The qualitative analysis of the result was shown in Table 6, 22 participating teachers responded to their problems while using music in English teaching, which can be categorized into four main aspects by using content analysis.

TABLE 6

Summary Of Other Problems About Teachers Using Music (N=22)

\begin{tabular}{|c|c|c|c|}
\hline Problem category & $\mathrm{n}$ & $\%$ & Keynotes from item 25 \\
\hline - inappropriate language uses in music & 12 & $54.6 \%$ & spoken language; grammar errors; idioms, slang, dirty phrases. \\
\hline - teacher personal issues & 6 & $27.3 \%$ & $\begin{array}{l}\text { personal not so interesting in music; little experience of using music; } \\
\text { lack in confidence of music. }\end{array}$ \\
\hline - contents of music & 3 & $13.6 \%$ & limitation of contents variety; content inappropriate. \\
\hline - students' learning styles & 1 & $4.5 \%$ & unknown students like music or not. \\
\hline
\end{tabular}

As illustrated in Table 6 above, the biggest problem responded by the most participants $(54.6 \%)$ was considering the language uses in music were inappropriate, such as the wrong grammatical forms, too many dirty phrases, etc. Then, as for the second problem, $27.3 \%$ of the teachers thought that the problems pertaining to themselves like teachers lacked the experience of using music in English teaching, or teachers were personally not so interested in music. The third problem was about the contents of music, $13.6 \%$ of the teachers indicated nowadays the contents of music were limited and some contents were inappropriate for secondary students. And there was one teacher who considered it was hard for teachers to identify their students' styles, thus, teachers cannot decide to use music or not, and to use what kind of music.

\section{DISCUSSION AND RECOMMENDATION FOR FUTURE RESEARCH}

The results of this study indicated that English teachers' personal attitudes toward music were significantly positive, as well as the beliefs in using music to teach English and music benefits for English learning. As in the results, the highly positive attitude is held by the teachers regarding music as a flexible tool and the authentic materials for English teaching, which implied that English teachers in the current study strongly believe in the pedagogical benefits and values of using music in their English teaching. Similarly, the English teachers' beliefs in music benefits for English learning are also positive, which indicated that English teachers in the current study have strong realizations that music could benefit English language learning, such as help the memorization, create a relaxing learning context, etc. Overall, the findings in the current study are parallel to the previous research studies of Tse (2013) in Malaysia and Sevik (2011) in Turkey. Tse (2013) concluded that Malaysian teachers have perceptions about the high values of using songs in ESL teaching, and the results in Sevik's (2011) research showed that Turkish EFL teachers hold strong beliefs in the value and effectiveness of using music in EFL teaching as well.

Surprisingly, the results of the intentions of using music in English teaching mismatched with the teachers' attitudes and beliefs. The quite low frequency of using music in teachers' daily English teaching was indicated in the result, especially teachers never use music to teach English grammar or writing and reading skills. In other words, even though English teachers hold significantly positive attitudes and beliefs in using music in English teaching, actually they somehow do not use music frequently as a teaching tool to accomplish their teaching intentions, which can be explained by the problems that English teachers reflected in the current study. By the quantitative and qualitative analysis of the problems, the reasons could be discovered as 1) teachers consider the low quality of the appropriate language uses in music, and 2) teachers lack the relevant training and experience to use music effectively and confidently in English teaching.

Therefore, further study can focus on analyzing the language uses in the lyrics of pop music, in order to help teachers find out more appropriate music that can be used in teaching. And further study also can explore the relevant training course for English teachers to learn how to use music effectively with different teaching purposes in English class.

However, there are a few limitations to the current study. The number of participants in the current study was limited. Then, the time for collecting data was a one-day stance. Finally, the data were collected only by the questionnaire.

\section{REFERENCES}

[1] Bidelman, G. M., Hutka, S., \& Moreno, S. (2013). Tone Language Speakers and Musicians Share Enhanced Perceptual and Cognitive Abilities for Musical Pitch: Evidence for Bidirectionality between the Domains of Language and Music. PLoS ONE 8(4): e60676. doi:10.1371/journal.pone.0060676.

[2] Campbell, G. D. (2000). Chapter 2: The Music Of Mozart. The Mozart Effect For Children. New York: HarperCollins Publisher.

[3] Dobrian, C. (1992). Music and Language. Retrieved 11 Aug. 2019, from http://music.arts.uci.edu/dobrian/CD.music.lang.htm.

[4] Gordon, R. L., Magne, C. L., \& Large, E. W. (2011). EEG Correlates of Song Prosody: a new look at the relation-ship between linguistic and musical rhythm. Frontiers in Psychology, 2(352): 352. doi: 10.3389/fpsyg.2011.00352.

[5] Hallam, S. (2010). The power of music: Its impact on the intellectual, social and personal development of children and young people. International Journal of Music Education, 28(3), 269-289. doi: 10.1177/0255761410370658. 
[6] Krashen, D. S. (2009). Principles and Practice in Second Language Acquisition [Adobe Digital Editions version]. Retrieved 11 Aug. 2019, from http://www.sdkrashen.com/content/books/principles_and_practice.pdf.

[7] Medina, S. (1993). The effect of music on second language vocabulary acquisition. FEES News (National Network for Early Language Learning), 6(3), 1-8.

[8] Mishan, F. (2005). Designing Authenticity into Language Learning Materials. Bristol: Intellect Books.

[9] Mora, C. F. (2000). Foreign Language Acquisition and Melody Singing. ELT Journal, 54(2), 146-152.

[10] Mora, C. F., Fuentes, T. C., \& Wermke, K. (2011). Melodies that help: The Relation between Language Aptitude and Musical Intelligence. Anglistik International Journal of English Studies, 22(1), 101-118.

[11] Murphey, T. (1992a). Music and Song. Oxford: Oxford University Press.

[12] Murphey, T. (1992b). The Discourse of Pop Songs. TESOL Quarterly, 26(4), 770-774. Retrieved 13 Sept. 2019, from http://dx.doi.org/10.2307/3586887.

[13] Nunan, D. (2004). Task-Based Language Teaching. Cambridge: Cambridge University Press.

[14] Patel, A. D. (2003). Language, music, syntax and the brain. Nature Neuroscience, 6(7), 674-681.

[15] Posedel, J., Lisa, E., Benjamin. S., \& Catherine, F. (2012). Pitch perception, working memory, and second-language phonological production. Psychology of Music, 40(4), 508-517.

[16] Rixon, S. (1986). Developing listening skills. London: Macmillan Publishers Limited.

[17] Sevik, M. (2011). Teacher views about using songs in teaching English to young learners. Educational Research and Review, 6(21), 1027-1035. doi: 10.5897/ERR11.250.

[18] Shen, C., X. (2009). Using English Songs: an Enjoyable and Effective Approach to ELT. English Language Teaching, 2(1), 8894. doi: 10.5539/elt.v2n1p88.

[19] Tse, A. Y. H. (2013). Malaysian Teachers Perspectives on Using Songs in English Language Teaching. International Journal of Social Science and Humanity, 5(1), 87-89.

Xiaowei Xi was born in Guiyang, Guizhou province, China in 1989. SHE is currently a Ph.D. candidate in ELT (English Language Teaching) at Language Institute, Thammasat University, Thailand. She received her Master's degree in TEFL (Teaching English as a Foreign language) from Chulalongkorn University, Thailand. Her research interests are English language pedagogy, learning motivation, and genre-based discourse analysis. 